\title{
Separation of functionally divergent muscle precursor cell populations from porcine juvenile muscles by discontinuous Percoll density gradient centrifugation
}

\author{
Claudia Miersch, Katja Stange and Monika Röntgen ${ }^{*}$
}

\begin{abstract}
Background: Satellite cells (SC) and their descendants, muscle precursor cells (MPC), play a key role in postnatal muscle development, regeneration, and plasticity. Several studies have provided evidence that SC and MPC represent a heterogeneous population differing in their biochemical and functional properties. The identification and characterization of functionally divergent SC subpopulations should help to reveal the precise involvement of SC/MPC in these myogenic processes. The aim of the present work was therefore to separate SC subpopulations by using Percoll gradients and to characterize their myogenic marker profiles and their functional properties (adhesion, proliferation, and differentiation).
\end{abstract}

Results: SC/MPC from muscles of 4-day-old piglets were isolated by trypsin digestion and enriched by Percoll density gradient centrifugation. A mixed myogenic cell population was obtained from the $40 / 70 \%$ interface (termed: mixed P40/70) of a 25/40/70\% Percoll gradient. Thereafter, by using a more stepped 25/40/50/70\% Percoll gradient, mixed P40/70 was divided into subpopulation 40/50 (SP40/50) collected from the 40/50\% interface and subpopulation 50/70 (SP50/70) collected from the 50/70\% interface.

All three isolated populations proliferated and showed a myogenic phenotype characterized by the ability to express myogenic markers (Pax7, MyoD1, Desmin, and MyoG) and to differentiate into myotubes. However, compared with mixed P40/70, SP40/50 and SP50/70 exhibited distinct functional behavior. Growth kinetic curves over $90 \mathrm{~h}$ obtained by the XCELLigence system and proliferation assays revealed that SP40/50 and mixed P40/70 constituted a fast adhering and fast proliferating phenotype. In contrast, SP50/70 showed considerably slower adhesion and proliferation. The fast-proliferating SP40/50 showed the highest myogenic differentiation potential with higher fusion rates and the formation of more middle-sized and large myotubes.

Conclusions: The described Percoll density gradient centrifugation represents a useful tool for subdividing pig SC/ MPC populations with divergent myogenic functions. The physiological role of SC subpopulations during myogenesis and the interaction of these populations can now be analyzed to a greater extent, shedding light on postnatal growth variations in pigs and probably in other animals.

Keywords: Pig, Satellite cells, Myogenic marker expression, Functional heterogeneity, Primary muscle cell culture, Differentiation

\footnotetext{
* Correspondence: roentgen@fbn-dummerstorf.de

Leibniz Institute for Farm Animal Biology (FBN), Institute of Muscle Biology and Growth, Growth and Development Unit, Wilhelm-Stahl-Allee 2, 18196 Dummerstorf, Germany
} 


\section{Background}

Skeletal muscles are composed of myofibers, mainly formed during prenatal development by embryonic and fetal myoblast populations [1, 2]. Only after the establishment of primary and secondary myofibers can socalled satellite cells (SC) be morphologically defined by their typical position between the basal lamina and the sarcolemma of the muscle fibers [3, 4]. During peri- and postnatal growth, $30-60 \%$ of the nuclei in porcine muscle are proliferating SC [5], and a high proportion of their progeny differentiates to fuse with adjacent myofibers thereby providing the main source of new myonuclei [6-8]. In this rapid growth phase, the number of SC constantly declines representing $2-5 \%$ of nuclei in adult muscle $[9,10]$. Simultaneously, increasing numbers of $\mathrm{SC}$ exit the cell cycle to form the adult quiescent stem cell pool. Quiescent SC are able to re-enter the cell cycle in response to activating stimuli (e.g., injury or physical activity) to participate in muscle maintenance and regeneration [11, 12]. During the quiescent phase, SC express the transcription factors paired box 7 (Pax7) and myogenic factor 5 (Myf5) [13-15]. About 10\% of SC never express Myf5 ( $\mathrm{Pax}^{+} / \mathrm{Myf5}^{-}$cells) and are thought to represent the "true" adult satellite stem cell pool [13]. Activated and proliferating SC are characterized by the expression of MyoD1 [16-18]. Both Myf5 and MyoD are important in determining muscle cell fate, either by regulating a return to the quiescent state to renew the SC pool or by initiating cellular differentiation accompanied by Pax7 downregulation and the induction of the early differentiation marker Myogenin (MyoG) $[15,19]$. Terminally differentiated cells express sarcomeric myosin heavy chain (MHC) proteins $[1,20]$. These cells fuse with each other to form nascent myotubes and/or fuse to differentiated muscle fibers [9].

In most studies, SC, myogenic precursor cells (MPC), and myoblasts are obtained from skeletal muscle by the dissociation of whole muscle by using mechanical procedures combined with enzymatic digestion [2, 21]. However, these isolates/cultures contain myofibrillar debris and are a mixture of myogenic and non-myogenic cells, mostly erythrocytes and fibroblasts [21-23]. This cellular impurity can be reduced by the use of enrichment procedures such as fluorescence-activated cell sorting [24], differential centrifugation [25], the preplate technique [25-27], or Percoll density gradient centrifugation [28-30]. In the Percoll density gradient fractionation system, several layers of solutions with different Percoll concentrations and, thus, densities are used to separate myogenic cells from non-myogenic cells $[23,31]$. After centrifugation, cell fractions having different densities appear at the interfaces between the Percoll layers and can be collected. However, density gradient centrifugation is rarely used to separate the enriched myogenic cells further into functionally divergent subpopulations, despite this technique having been originally established to separate mononuclear blood cell populations [32]. In a study of Che et al. [31], an association was postulated between cell density and cell maturity as measured via molecular marker expression, but no information was provided about the functional properties of the separated cell populations.

Accumulating evidence indicates that SC populations are heterogeneous not only because of differences in their myogenic marker expression, but also because of their developmental stage (fetal, postnatal, adult) $[1,33,34]$ and their myogenic function $[35,36]$. In the postnatal period, nearly $80 \%$ of SC/MPC are highly proliferative $[5,37,38]$, whereas the remaining cells divide slowly $[37,39]$ and retain stem cell properties for long-term self-renewal [40].

To date, several methods have been described to isolate and cultivate porcine SC and MPC [23, 41-44], but the heterogeneity of these cells, particularly during the postnatal growth phase, has rarely been considered so far. One reason for this is the lack of an effective but simple method to separate distinct myogenic cell populations by any other way than analyzing them for myogenic marker expression. The investigation of the heterogeneity of mixed (mass) cultures of SC/MPC and myoblasts is however a prerequisite for the better understanding of the origins and targeted modulation of growth phenotypes and of certain pathological states. Recently, we have shown that the early postnatal development of functionally heterogeneous SC subpopulations is associated with the bioenergetic profile of these cells [45]. In the present study, we describe an adequate method for separating SC subpopulations by Percoll density gradient centrifugation enabling the investigation of the heterogeneity and interaction of SC/MPC by the examination the myogenic properties of the mixed myogenic population in comparison with the divided subpopulations.

\section{Methods \\ Animals}

The cells for the experiments were obtained from 4-dayold German Landrace piglets having a normal birth weight $(1.20 \pm 0.25 \mathrm{~kg})$ and raised in the experimental pig unit of the Leibniz Institute for Farm Animal Biology (FBN). Animal husbandry and slaughter followed the guidelines set by the Animal Care Committee of the State Mecklenburg-Western Pomerania, Germany, based on the German Law of Animal Protection.

\section{Isolation and cultivation of myogenic cells}

The right and left Musculus semimembranosus (SM) and the right and left Musculus longissimus dorsi (LD) were removed in one piece, trimmed of visible connective tissue, and weighed in phosphate-buffered saline (PBS) 
containing $25 \mathrm{mM}$ glucose, $14 \mathrm{mM}$ sucrose, $1000 \mathrm{U} / \mathrm{ml}$ penicillin (PAN Biotech), $1 \mathrm{mg} / \mathrm{ml}$ streptomycin (PAN Biotech), and $25 \mu \mathrm{g} / \mathrm{ml}$ amphotericin (PAN Biotech).

Dissected muscle tissue was washed and minced intensively with scissors before fractionated enzymatic digestion was performed for $2 \times 30$ min with $1 \times$ trypsin solution $(0.25 \%, 4000 \mathrm{U} / \mathrm{ml}$, Sigma Aldrich) in a water bath with stirring at $37{ }^{\circ} \mathrm{C}$. After being washed and filtered through gauze and fine nylon mesh $(20 \mu \mathrm{m})$, muscle-dissociated cells were subjected to Percoll (Sigma Aldrich) gradient density centrifugation $(1800 \mathrm{x} \mathrm{g}$ for $1 \mathrm{~h}$ ). The fractionated cells were re-suspended in growth medium ( $\alpha$ MEM Eagle, 20\% FBS, $100 \mathrm{U} / \mathrm{ml}$ penicillin/ streptomycin, $2.5 \mu \mathrm{g} / \mathrm{ml}$ amphotericin, and $0.05 \mathrm{mg} / \mathrm{ml}$ gentamycin; all from PAN Biotech).

Cell dissociation and digestion were performed as described by Mau et al. [23], but the employed Percoll density gradients were modified. Mau et al. [23] utilized a $25 \%, 40 \%$, and $90 \%$ Percoll gradient to enrich SC/MPC at the $40 / 90 \%$ interface. The cell isolates obtained with this gradient were free from myofibril fragments, debris, and fibroblasts but were highly contaminated with erythrocytes. Therefore, as described by Bischoff and Heintz [46], the $90 \%$ Percoll layer was substituted by a $70 \%$ Percoll layer in our study. This procedure resulted in a clear separation of MPC from erythrocytes, which were now mainly found at the bottom of the tube. To isolate distinct SC/MPC subpopulations, two Percoll gradients composed of $25 \%, 40 \%$, and $70 \%$ (gradient 1 ) or $25 \%, 40 \%, 50 \%$, and $70 \%$ (gradient 2) Percoll layers were used. When gradient 1 was used, cells were taken from the $40 / 70 \%$ interface and termed mixed population 40/70 (mixed P40/70). When gradient 2 was used, mixed $\mathrm{P} 40 / 70$ was divided into $40 / 50$ and $50 / 70$ subpopulations (SP40/50 and SP50/70) that were obtained from the 40/ $50 \%$ and $50 / 70 \%$ interfaces, respectively (see Fig. 1a). Cells were seeded at approximately $0.5 \times 10^{6} \mathrm{cells} / \mathrm{cm}^{2}$ in dishes coated with collagen type I (Greiner Bio-one) and cultured under a humidified atmosphere with $5 \% \mathrm{CO}_{2}$ at $37^{\circ} \mathrm{C}$. At $24 \mathrm{~h}$ after seeding, the cells were washed with PBS containing $100 \mathrm{U} / \mathrm{ml}$ penicillin/streptomycin, $2.5 \mu \mathrm{g} / \mathrm{ml}$ amphotericin, and $0.05 \mathrm{mg} / \mathrm{ml}$ gentamycin. Bacterial and fungal contamination of cells was tested via inoculation of CASO Bouillon Tryptic Soy Broth (Merck) and Thioglycolate medium EP (Merck).

For passaging, cultured SC/MPC were detached by using HyClone HyQTase (Thermo Fisher Scientific), and the reaction was stopped by adding PBS containing $10 \%$ FBS. After centrifugation $\left(10 \mathrm{~min}, 300 \mathrm{~g}, 10{ }^{\circ} \mathrm{C}\right)$, cells were re-suspended in growth medium, and the cell number was determined. From the first passage on, SC were cultured on Primaria ${ }^{\circ}$ tissue culture dishes (VWR International) in growth medium.

\section{Determination of cell number, cell size, and viability}

Cell number, cell size, and viability were quantified by using the Countess Automated Cell Counter (Thermo Fisher Scientific) following the manufacturer's instructions. This
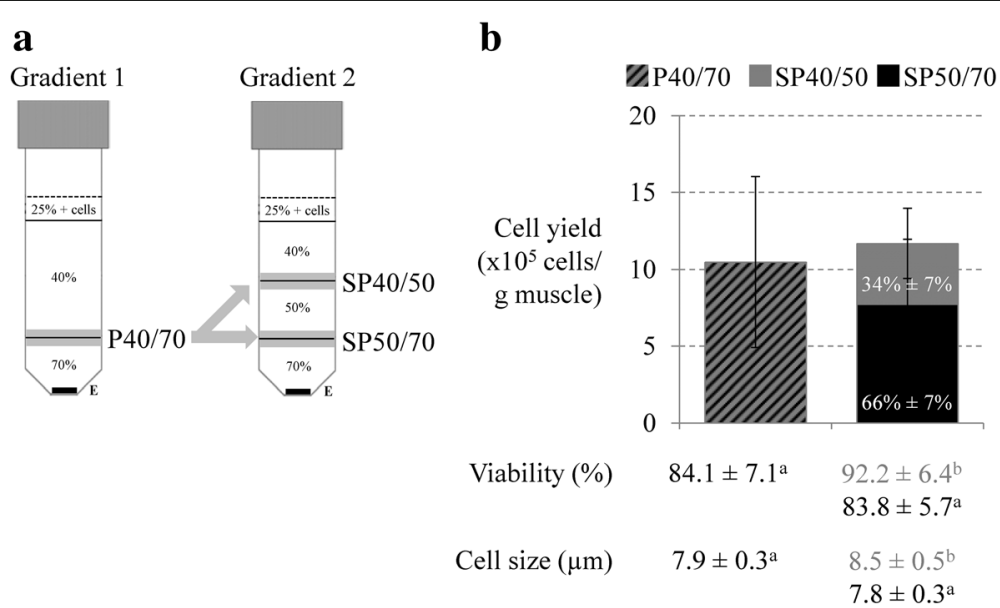

Fig. 1 Overview of Percoll gradients employed and cell characteristics directly after isolation. a Trimmed muscle fragments from SM and LD muscle of 4-day-old piglets were digested with $0.25 \%$ trypsin and enriched at different Percoll layers by density gradient centrifugation. The collected cell populations are marked in gray, the erythrocyte fraction in black (E). A mixed myogenic population was isolated from the 40/70\% interface (mixed P40/70) of a 25\%, 40\%, and 70\% Percoll gradient and was separated into 40/50\% and 50/70\% subpopulations (SP40/50 and SP50/70) by the use of a second Percoll gradient with 25\%, 40\%, 50\%, and 70\% layers. b Cell yield, viability, and cell size of isolated cells from SM and LD muscle were determined, directly after isolation, with the Countess Automated Cell Counter. All data represent means \pm SD, $n \geq 7$ animals. The cell yield from SP40/50 and SP50/70 together did not differ from mixed P40/70, but SP40/50 showed a higher cell viability and cell size. A t-test was performed for the statistical analysis of differences in cell yield between mixed P40/70 and both subpopulations together. For the statistical analysis of cell viability, a Kruskal-Wallis One-Way ANOVA on Ranks was performed following a pairwise multiple comparison procedure (Dunn's method). An ANOVA with the Holm-Sidak post-hoc test was performed for the statistical analysis of cell size. Letters mark significant differences within the populations $(p \leq 0.05)$ 
system utilizes an image analysis algorithm combined with trypan blue staining to obtain accurate counts of cells, cell size, and viability.

\section{Analysis of myogenic marker expression with flow cytometry}

Cultured SC were detached at day 4 and day 8 after isolation by using HyClone HyQTase, and the reaction was stopped by adding PBS containing 10\% FBS. After centrifugation $\left(10 \mathrm{~min}, 300 \mathrm{~g}, 10{ }^{\circ} \mathrm{C}\right)$, cells were resuspended in $1 \mathrm{mM}$ EDTA in PBS and fixed in $4 \%$ paraformaldehyde (PFA). Following fixation, cells were permeabilized with $0.1 \%$ (Desmin, MyoG) or $0.5 \%$ (Pax7, MyoD1) Triton X-100 in PBS, blocked with normal rabbit serum, and incubated overnight with the respective primary antibody: mouse anti-Desmin (clone D-33, DAKO, 1:80), mouse anti-Pax7 (Developmental Studies Hydridoma Bank, 1:50), mouse anti-MyoG (clone F5D, abcam, 1:50), or mouse anti-MyoD1 (clone 5.2F, abcam, 1:200). A portion of each sample was incubated with normal rabbit serum instead of primary antibody as a negative control. After two additional washing steps, samples were incubated with a rabbit anti-mouse Alexa488 antibody (Thermo Fisher Scientific, 1:1000) for $1 \mathrm{~h}$ at room temperature and washed again. In total, 5000 events per sample were analyzed by using an argon-equipped Gallios Flow Cytometer (Beckman Coulter) and evaluated with Kaluza software (Beckman Coulter).

\section{Proliferation rate}

To determine cell proliferation rate, cells were seeded at similar densities $\left(3-4 \times 10^{5}\right.$ cells $)$ on Primaria ${ }^{\circ}$ tissue culture dishes, and the cell number was determined after passaging by using the Countess Automated Cell Counter. Fold change was calculated as the difference between the final and the initial cell number.

\section{Impedance-based measurement of cell adhesion and proliferation}

The xCELLigence (RTCA-SP, ACEA Biosciences Inc.) was used according to the manufacturer's instructions for the continuous real-time monitoring of cell adhesion and proliferation by cell-electrode impedance [47] displayed as the dimensionless Cell Index (CI). By using an RTCA Analyzer, electrical impedance changes were measured across interdigitated microelectrodes integrated into the bottom of a specialized 96-well plate (E-Plate ${ }^{\circ}$ 96) and sent to the RTCA control subunit. The latter used the RTCA software (version 2.0) for CI calculations from the frequency-dependent electrode resistances and real-time display of data. Specific details of the xCELLigence technology are described by Atienza et al. [48] and Ke et al. [49].
The background impedance of E-Plate 96 was determined with growth medium only. Subsequently, 5000 or 40,000 cells per well were plated in a final volume of $200 \mu \mathrm{l}$ growth medium. Based on initial growth curve experiments (data not shown), a high cell density of 40,000 cells per well was chosen to analyze cell adhesion (adhesion assay). In order to enable exponential growth, a low cell density of 5000 cells per well was used to examine the proliferation capacity of cells (proliferation assay). The cells were seeded in the E-Plate ${ }^{\circ}$ 96, the plate was placed into a $\mathrm{CO}_{2}$-incubator, and the $\mathrm{CI}$ was monitored every $15 \mathrm{~min}$ over a period of $90 \mathrm{~h}$. Cells were provided with fresh medium after $48 \mathrm{~h}$. The RTCA software was used to calculate growth parameters: the slope during the cell adhesion phase $(\Delta \mathrm{CI} / \Delta$ time), CI decrease after medium change, the doubling time (DT) during the logarithmic growth phase, and the time to reach half of the maximal $\mathrm{CI}$ value $\left(50 \%\right.$ of $\mathrm{CI}_{\max }$ ) during the experiment. In all experiments, each subpopulation was measured in quadruplicate, and experiments were repeated at least 5 times with cells from different animals.

\section{Differentiation assay}

For myogenic differentiation, cells were seeded directly after isolation (mixed P40/70 and SP40/50: $1.5 \times 10^{5}$ cells/well; SP50/70: $3 \times 10^{5}$ cells/well) on Primaria 24 well plates coated with Matrigel (growth factor reduced; 1:50, BD Biosciences) and cultivated in growth medium. At $80-90 \%$ confluency, cells were washed with PBS to remove excessive serum, and differentiation medium with $2 \%$ FCS was added. Medium was changed regularly. Finally, cells were washed with PBS and fixed in 4\% PFA. A Nikon Diaphot 300 microscope and Olympus cell ${ }^{\mathrm{F}}$ software were used to examine cells light microscopically.

Immunofluorescence and quantification of differentiation The fixed and differentiated cells were permeabilized with $0.1 \%$ (Desmin) or $0.3 \%$ (MHC) Triton X-100, blocked with normal rabbit serum, and incubated with the primary antibody, namely mouse anti-Desmin (clone D-33, DAKO, 1:80) or mouse anti-skeletal fast Myosin (MHC; clone MY-32, Sigma Aldrich, 1:400), overnight. After being washed with PBS, the samples were incubated with a rabbit anti-mouse Alexa488 antibody (Thermo Fisher Scientific, 1:1000) for $1 \mathrm{~h}$ at room temperature, and subsequently, cell nuclei were stained with DAPI (15 min, $1 \mu \mathrm{g} / \mathrm{ml})$. For fluorescence microscopy, the Nikon Diaphot 300 microscope and Olympus cell ${ }^{\mathrm{F}}$ software were used. Micrographs were merged by using Adobe Photoshop CC 2017; contrast and brightness were adjusted to the same degree in every sample group. 
MHC + myotubes containing $\geq 2$ nuclei were encircled to determine the myotube area by using ImageJ $1.49 \mathrm{v}$. For each experiment, 10-12 random sections per population were analyzed. Micrographs of the Desminstained cells were used to determine cell fusion rate. The number of nuclei in the fused multinucleated cells $(\geq 2$ nuclei) was divided by the total number of visible nuclei in 5 random sections for each experiment and subpopulation. Experiments were repeated independently three times with cells obtained from three animals.

\section{Statistical analysis}

All data are presented as means \pm standard deviation (SD), except in Figs. 2 and $4 \mathrm{~b}$ which show Box-Whisker plots with median and $25 \% / 75 \%$ quartiles. Statistical analyses were performed by using SigmaPlot 13.0 (Systat Software Inc.). All data sets were tested for normality (Shapiro-Wilk) and equal variance (Brown-Forsythe). If the tests for normality and equal variances were passed, the statistical significance of the data was assessed by Student's t-test (Fig. 1b) or, for the comparison of all three subpopulations, by One-Way ANOVA followed by the Holm-Sidak method as a pairwise comparison test. If the normality test or the equal variance test failed, Kruskal-Wallis One-Way ANOVA on Ranks was performed with the Tukey test (equal sampling) or Dunn's method (unequal sampling) as a pairwise comparison procedure. A $p$-value of $\leq 0.05$ was considered to be statistically significant.

\section{Results}

Separation of SC/MPC subpopulations by various Percoll density gradients

SC isolation and enrichment by tissue digestion with 0.25\% trypsin followed by Percoll gradient centrifugation were performed according to Mau et al. [23] with the exception that the Percoll gradient was changed from $25 \%, 40 \%, 90 \%$ to $25 \%, 40 \%, 70 \%$ (gradient 1 ) to remove erythrocytes. The protocol of Mau et al. has been shown to achieve SC-derived myoblasts cultures of high purity [23]. Nevertheless, primary isolates of muscle-derived cells are highly heterogeneous and can contain SC and MPC from different lineages and at variable developmental stages [31]. To consider the heterogeneity of SC/ MPC, the mixed myogenic population (mixed P40/70) isolated by gradient 1 was split up into two subpopulations (SP40/50 and SP50/70) by introducing an additional 50\% Percoll layer between the $40 \%$ and $70 \%$ Percoll layers (gradient 2, see Fig. 1a).

Indeed, directly after isolation, the total cell yield of SP40/50 and SP50/70 together was similar to that of mixed P40/70 (Fig. 1b). However, freshly isolated SP40/ 50 and SP50/70 accounted for $34 \%$ and $66 \%$ of the total cell yield, respectively. Furthermore, SP40/50 showed a

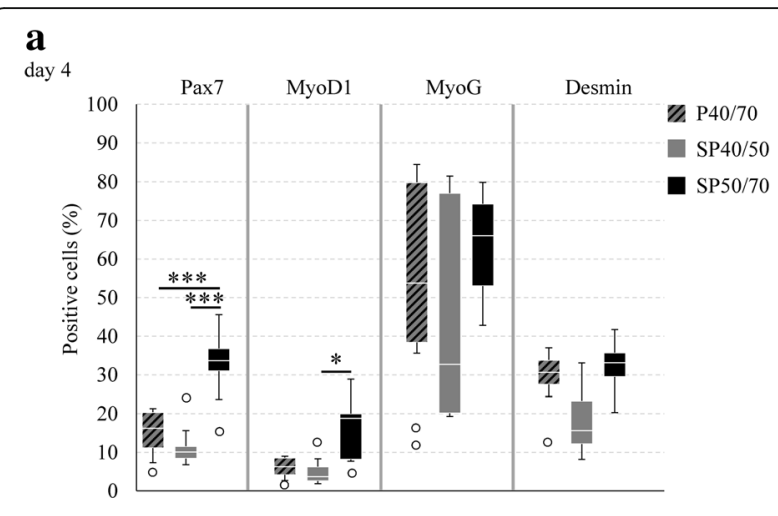

b

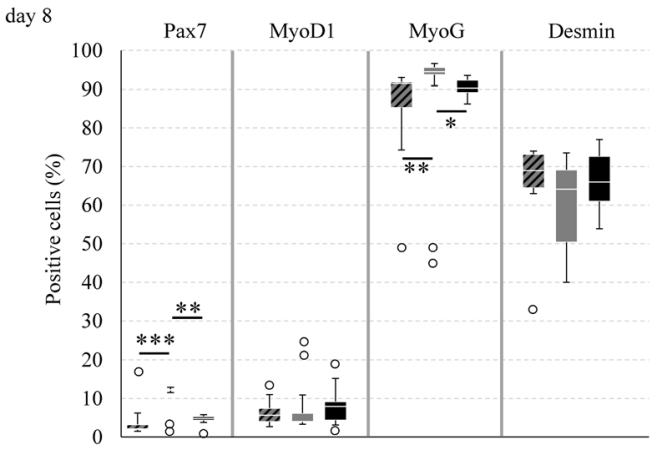

Fig. 2 Myogenic marker expression of isolated SC/MPC populations. Flow cytometric analysis of immunofluorescence-stained SC/MPC from SM and LD muscle cultured for 4 days (a) and 8 days (b) in growth medium. The cells were immunostained for Pax7, MyoD1, MyoG, and Desmin. Percentages of positive cells in each sample are presented as Box-Whisker plots with the median and the maximum 1.5 of the interquartile range (Q1-Q3). Outliers are included in the figure as circles but were excluded from statistical analysis. All populations expressed the selected myogenic markers, whereas a higher proportion of cells were positive for MyoG and Desmin, which are markers for terminally committed myogenic cells. Statistical analysis was performed by ANOVA (with the Holm-Sidak method as a pairwise multiple comparison procedure) or the Kruskal-Wallis One-Way ANOVA on Ranks (with Dunn's method as a pairwise multiple comparison procedure), ${ }^{*} p \leq 0.05,{ }^{* *} p \leq 0.01,{ }^{* *} p \leq 0.001$, $n=4-9$ animals

significantly higher cell viability and cell size compared with mixed P40/70 and SP50/70.

To characterize the identity/purity and to assess the cell fate of the isolated cells, the expression of several myogenic markers was analyzed by flow cytometry during culture (Fig. 2a and b). SC and committed MPC are characterized by the expression of the transcription factors Pax7 and MyoD1, whereas terminally committed MPC are characterized by MyoG and Desmin expression [50]. Over the three populations, Pax7 and MyoD1 were expressed in approximately $12-30 \%$ and $6-13 \%$ of the cells, whereas MyoG and Desmin were expressed in approximately $45-63 \%$ and $18-32 \%$ of the cells at day 4 of culture (Fig. 2a). At day 8 of culture, the percentage of 
Pax7+ and MyoD1+ cells decreased in all populations compared with day 4, whereas the percentage of MyoG+ and Desmin + cells increased, resulting in 87-94\% MyoG + and 60-66\% Desmin + cells (Fig. 2b). Looking at differences between mixed P40/70, SP40/50, and SP50/70 at day 4 of culture, we found that the proportion of Pax7+ cells was significantly higher in SP50/70 compared with mixed P40/70 and SP40/50 (Fig. 2a). In addition, a difference in the proportion of MyoD1 was evident between SP40/50 and SP50/70. During culture, the proportion of Pax7+ cells decreased in mixed P40/70 and in SP50/70, and simultaneously, more SP40/50 cells were MyoG+ in comparison with mixed $\mathrm{P} 40 / 70$ and with SP50/70 (Fig. 2b).

\section{Adhesion and proliferation properties of isolated SC/MPC populations}

To quantify possible functional differences between mixed $\mathrm{P} 40 / 70$ and the subpopulations, proliferation rates were determined between day 0 and day 4 and between day 4 and day 8 of culture. In the period from day 0 to day 4, the proliferation rate of SP40/50 was significantly higher (3.2-fold), whereas the proliferation rate of SP50/ 70 (0.9-fold) was similar to that of mixed P40/70 (Fig. 3). Between day 4-8, the differences between mixed P40/70 and SP40/50 disappeared, but the proliferation rate of SP50/70 was still significantly reduced compared with mixed P40/70 and SP40/50.

To investigate cell behavior in more detail, real-time growth curves for mixed P40/70 and the subpopulations were continuously recorded over a period of $90 \mathrm{~h}$ by the $\mathrm{xCELLigence} \mathrm{system.} \mathrm{This} \mathrm{system} \mathrm{measures} \mathrm{impedance}$

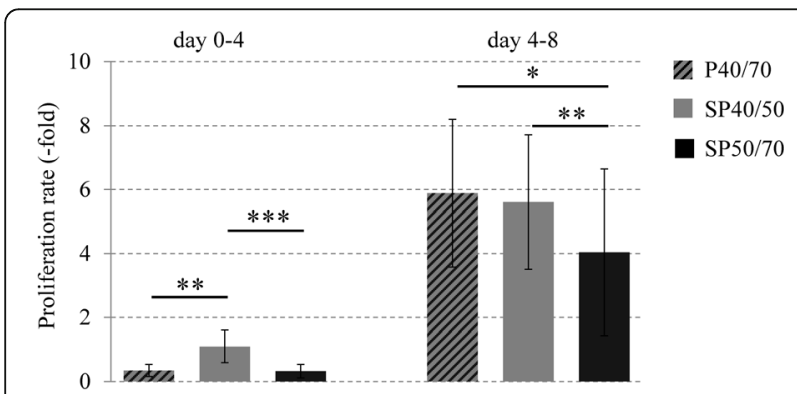

Fig. 3 Proliferation rates of isolated SC/MPC populations. Proliferation rates of isolated populations from SM and LD muscles were calculated by using the changes in cell number between passaging (from day 0-4 and day 4-8 after isolation). SP40/50 showed significantly higher proliferation rates between day $0-4$, in comparison with mixed P40/70 and SP50/70. The differences in proliferation between SP40/50 and mixed P40/70 disappeared between day 4-8, whereas SP50/70 retained lower proliferation rates than SP40/50 and mixed P40/70. Data are presented as means $\pm S D, n \geq 10$ animals. Statistical analysis of differences in proliferation was performed with a Kruskal-Wallis One-Way ANOVA on Ranks followed by a pairwise multiple comparison procedure (Dunn's method), and significant differences are shown $\left({ }^{*} p \leq 0.05\right.$, ${ }^{* *} p \leq 0.01,{ }^{* * *} p \leq 0.001$ ) changes caused by the presence of cells and calculates them as the dimensionless Cell Index (CI). Impedance readings are affected by the number of cells, the cell size, and the quality of their attachment and spreading, but changes in CI correlate with cell number throughout the experiment as has been confirmed by classic endpoint measurements [51, 52]. At the beginning of the experiment, cell size did not differ between the populations (mixed P40/70: $15.0 \pm 0.73 \mu \mathrm{m}, \mathrm{SP} 40 / 50: 14.9 \pm 0.63 \mu \mathrm{m}$, SP50/70: $14.8 \pm 0.71 \mu \mathrm{m}$ ). Representative original growth curves are given in Fig. 4a, and growth parameters from all experiments performed are summarized in Fig. 4b. In previous experiments, 5000 cells per well were selected as being the most suitable cell number to assess proliferation (proliferation assay). As adhesion is an important requirement for proliferation of cells, adhesion and spreading were also analyzed. Since a higher signal resolution is required for this experiment, adhesion assays were carried out with 40,000 cells per well.

In adhesion assays (black curves in Fig. 4a), the CI increased dramatically after seeding and reached a plateau after $\sim 8 \mathrm{~h}$ in all populations. However, the adhesion slope was significantly higher in mixed P40/70 $(0.59 \pm$ $0.13)$ and SP40/50 $(0.66 \pm 0.21)$ in comparison with SP50/70 (0.38 \pm 0.25$)$ (Fig. 4b). Interestingly, we observed that mixed P40/70 and SP40/50 were more sensitive to a mechanical stress induced by medium change in comparison with SP50/70 (Fig. 4a and b). This was reflected by a sharp decrease of the CI $(-57 \%$ for mixed P40/70, $-49 \%$ for SP40/50, and $-26 \%$ for SP50/70), indicating that a higher proportion of cells from mixed P40/70 and SP40/50 were rather weakly attached to the bottom of the well.

In proliferation assays (gray curves in Fig. 4a), the proliferative capacity was determined by calculating the doubling time (DT) and the time to reach half of the maximal $\mathrm{CI}$ value $\left(50 \%\right.$ of $\left.\mathrm{CI}_{\max }\right)$. The DT was similar for all three populations (mixed P40/70: 21.9 $\pm 6.4 \mathrm{~h}$, SP40/50: $19.6 \pm 3.6 \mathrm{~h}$, SP50/70: $20.0 \pm 4.0 \mathrm{~h}$ ), but cells of SP50/70 needed significantly longer to reach $50 \%$ of $\mathrm{CI}_{\max }$ (Fig. 4b, $53 \pm 11 \mathrm{~h}$ ) compared with cells of mixed P40/70 (45 \pm 9 h) and SP40/50 (45 $\pm 7 \mathrm{~h})$. A CI decrease after medium change, especially in mixed P40/70 and in SP40/50, was also seen in proliferation assays (gray curves).

\section{Myogenic differentiation potential of isolated SC/MPC populations}

As differentiation is a prerequisite for forming functional myogenic tissue, the differentiation potential of mixed $\mathrm{P} 40 / 70$ and the subpopulations was tested in vitro. Freshly isolated cells were cultured in growth medium, and before reaching confluence, medium was changed to serum-reduced differentiation medium. Mixed P40/70 

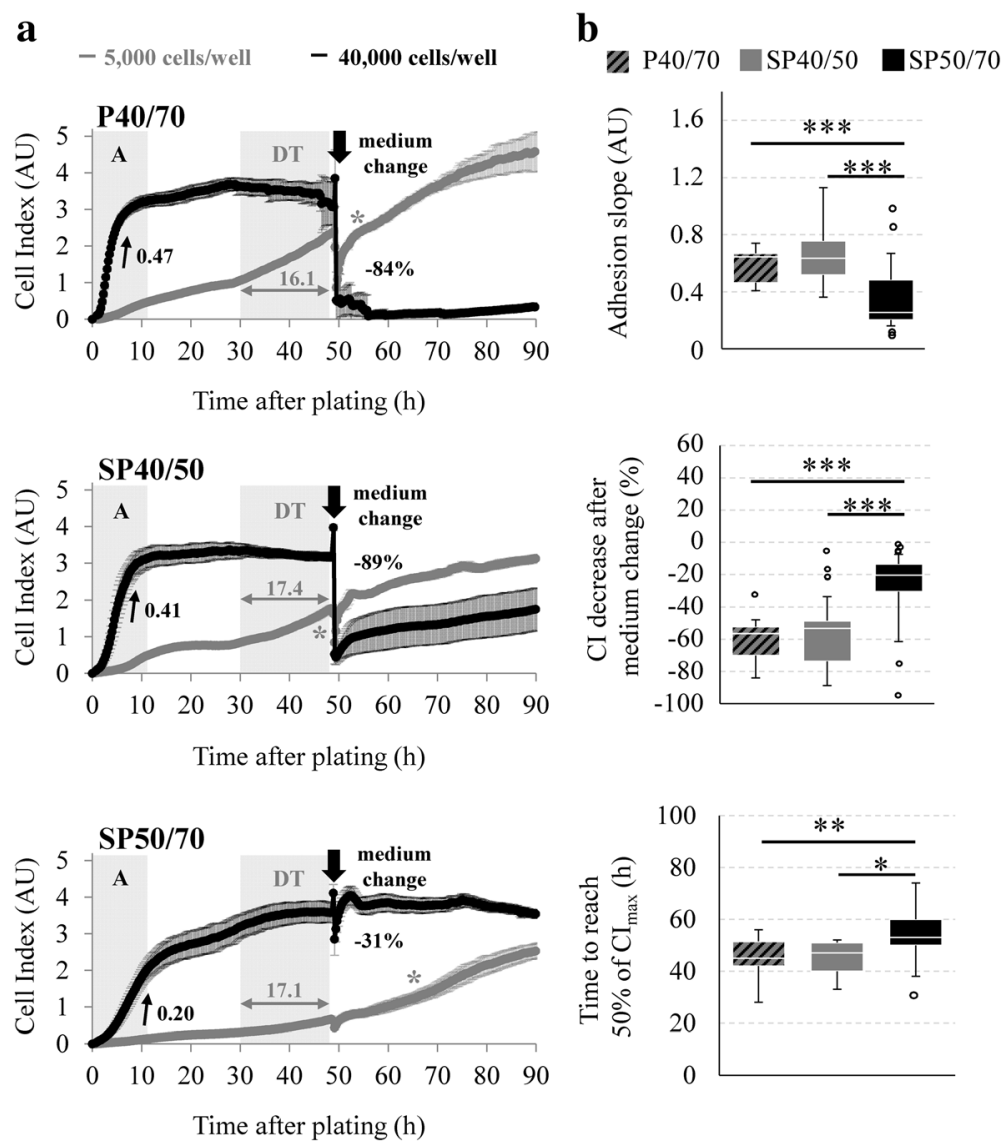

Fig. 4 Growth curves of isolated SC/MPC populations. a Representative original growth curves of cells from mixed P40/70, SP40/50, and SP50/70 started at day 8 of culture. The impedance-based XCELLigence system was used for real-time monitoring of adhesion and proliferation of SC populations seeded at densities of 5000 cells per well (gray) or 40,000 cells per well (black), respectively. In adhesion assays, growth curves were analyzed regarding the slope during the adhesion phase (A) and the $\mathrm{Cl}$ decrease after medium change. In proliferation assays, growth curves were analyzed with regard to the doubling time (DT) during the logarithmic growth phase and the time for $\mathrm{Cl}$ to reach half of its maximum value $(50 \% \mathrm{Cl}$, marked with *). Curves were obtained from quadruplicates measured in parallel for each condition, and representative results are shown as means \pm SD. $\mathbf{b}$ Box-Whisker plots are shown for selected growth parameters and include all experiments performed $\left(n=5-12\right.$ animals). Whiskers are presented with the maximum 1.5 of the interquartile range $\left(Q_{1}\right.$ $-\mathrm{Q}_{3}$ ), and the resulting outliers are included as circles. Statistical analysis of differences in growth parameters was performed by an ANOVA (adhesion slope, $50 \%$ of $\mathrm{Cl}_{\text {max }}$ ) or Kruskal-Wallis One-Way ANOVA on Ranks (Cl decrease after medium change) followed by a pairwise comparison test, and significant differences are marked with asterisks $\left({ }^{*} p \leq 0.05,{ }^{* *} p \leq 0.01,{ }^{* * *} p<0.001\right)$. All populations showed characteristic kinetic profiles, but measurable differences occurred between them. The slope during cell adhesion is significantly steeper in mixed P40/70 and SP40/50 in comparison with SP50/70. The Cl of mixed P40/70 and SP40/50 is influenced negatively by medium change, but significantly less dramatically in SP50/70. The time needed to reach 50\% of the maximum $\mathrm{Cl}\left(50 \%\right.$ of $\mathrm{Cl}_{\text {max }}$ ) value was different among the populations, whereas SP50/70 showed significantly higher values than mixed P40/70 and SP40/50

and both subpopulations, SP40/50 and SP50/70, showed the ability to differentiate into the myogenic lineage, as they fused to elongated multinucleated myotubes, which were clearly visible in phase contrast images and images from Desmin- or MHC-stained cultures (Fig. 5). However, significant quantitative differences were found between the populations (Figs. 5 and 6) with SP40/50 exhibiting the highest differentiation capacity followed by SP50/70 and mixed P40/70. The myotube-covered area, determined by the MHC signal positive area, was markedly higher in SP40/50 $\left(18,332 \pm 17,897 \mu^{2}\right)$ than in SP50/70 $\left(5816 \pm 1148 \mu^{2}\right)$ and mixed P40/70 $\left(4121 \pm 1432 \mu \mathrm{m}^{2}\right.$, Fig. 6a) cultures. In addition, compared with mixed P40/70 and SP50/70 cultures, a higher proportion of middle-sized and large myotubes $\left(\geq 10,000 \mu \mathrm{m}^{2}\right.$ ) formed in SP40/50 cultures (Fig. 6b), in accordance with the significantly higher fusion rate in SP40/50 cultures (Fig. 6c).

\section{Discussion}

In this study, we present an easily feasible method for separating two functionally divergent SC/MPC subpopulations from a mixed population of myogenic cells isolated from postnatal piglet muscles. As described by 


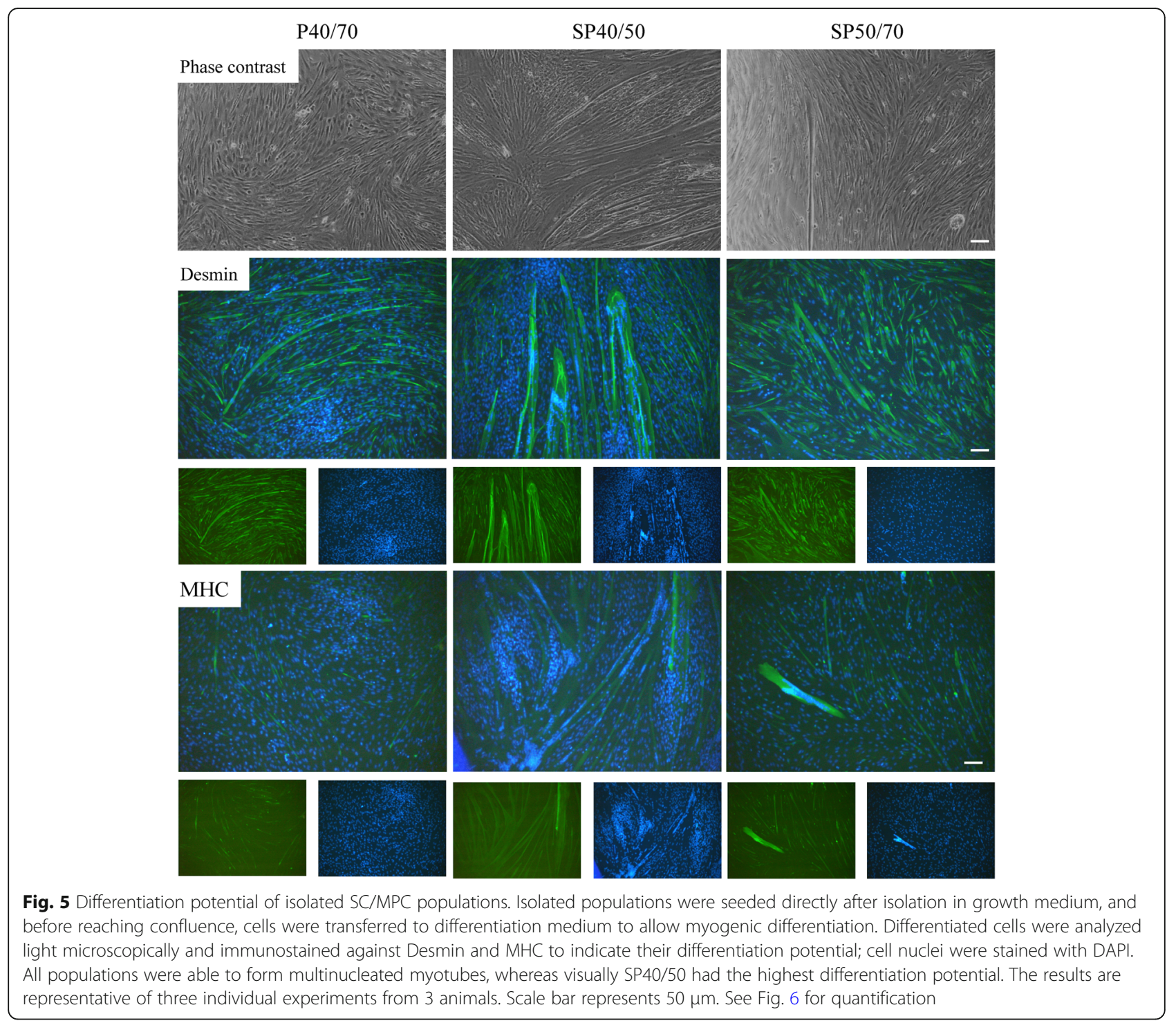

others [23, 28, 46], SC were released from muscle tissue by enzymatic digestion with $0.25 \%$ trypsin, and thereafter, a Percoll density gradient $(25 \%, 40 \%, 70 \%)$ was used to enrich SC/MPC at the $40 / 70 \%$ interface and to remove debris and non-myogenic cells such as fibrocytes [53] and in particular erythrocytes [46] from cell isolates. To obtain more information about the heterogeneity and interaction of SC/MPC, we divided the mixed 40/70 population into the $40 / 50$ and $50 / 70$ subpopulations by using a more stepped $25 \%, 40 \%, 50 \%, 70 \%$ Percoll gradient. The resulting subpopulations were characterized regarding their myogenic marker profiles and their functional behavior (adhesion, proliferation, and differentiation).

The proportion of myogenic cells was approved by the expression of Pax7 and/or MyoD1, and particularly by the high proportions of early differentiated, MyoG+ cells in day 4 (up to 63\%) and day 8 ( $\geq 90 \%$ ) cultures held under growth-promoting conditions. The marker expression analysis revealed that all isolated cell populations had a high degree of myogenic purity. Moreover, differentiation assays confirmed their ability to differentiate into the myogenic lineage. In several studies, Desmin rather than MyoG has been used to analyze the purity of SC isolates from piglet muscles [23, 54, 55]. Although the proportion of Desmin+ cells significantly increased from an average of $25 \%$ to $63 \%$ during culture in our study, it was clearly below the values observed for MyoG. The presence of Desmin during myogenic commitment has been shown to vary between rodents, chicken, and cattle [56, 57], and the temporal and spatial expression pattern of Desmin has not been precisely described in pig. Hence, we cannot exclude that Desmin is expressed later than MyoG during myogenesis in $\mathrm{SC} /$ 
$\mathbf{a}$

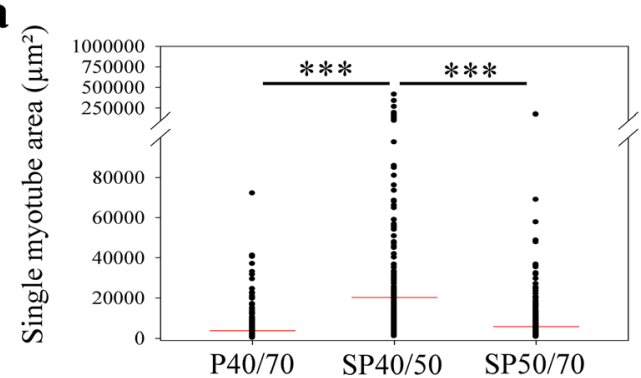

b

Small myotubes $\left(<10,000 \mu \mathrm{m}^{2}\right) \square$ Middle and large myotubes $\left(\geq 10,000 \mu \mathrm{m}^{2}\right)$

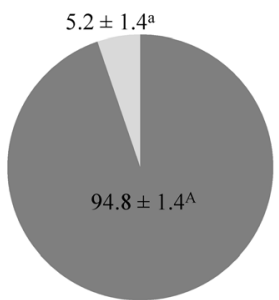

$\mathrm{P} 40 / 70$

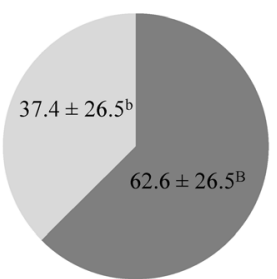

SP40/50

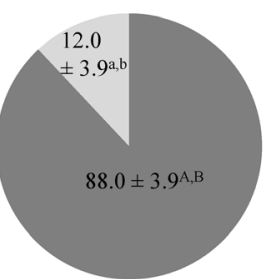

$\mathrm{SP} 50 / 70$

c

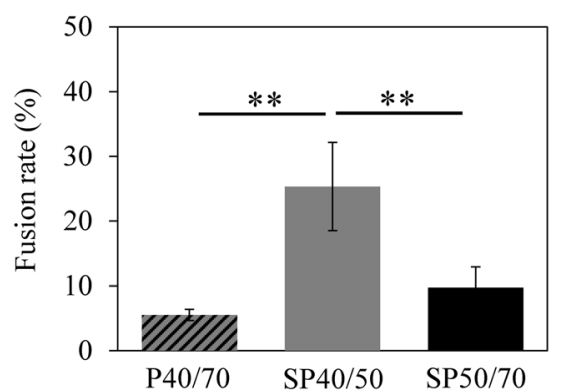

Fig. 6 Myotube size distribution and fusion rate of differentiated SC/MPC populations. a, b Quantitative analysis of MHC immunofluorescence images to determine myotube area. a Each point represents the size of a single MHC+ myotube that contains two or more nuclei, and the horizontal line illustrates the mean value. b Myotubes with a size of $<10,000{\mu m^{2}}^{2}$ were classified as small myotubes, whereas myotubes $\geq 10,000 \mu m^{2}$ were grouped as middle-sized and large myotubes. c Quantitative analysis of Desmin immunofluorescence images to determine fusion rate. SP40/50 contained more middle-sized and large myotubes, resulting in a significantly higher average myotube area in comparison with mixed P40/70 and SP50/70. Furthermore, significantly higher fusion rates were determined in SP40/50 compared with mixed P40/70 and SP50/70. The results represent three individual experiments from 3 animals. Statistical analysis was performed by a One-Way ANOVA (fusion rate) or Kruskal-Wallis One-Way ANOVA on Ranks (myotube area and distribution) followed by the corresponding pairwise comparison test, and significant differences are marked with asterisks in Fig. $6 a$ and $c\left({ }^{* *} p \leq 0.01\right.$, $\left.{ }^{* * *} p \leq 0.001\right)$ or letters in fig. $6 \mathrm{~b}(\mathrm{p} \leq 0.05)$

MPC isolated from neonatal piglets; this would explain the lower proportion of Desmin+ cells than MyoG+ cells in our cell populations. It should be noted that the absence of Desmin does not automatically point to a non-myogenic cell. Therefore, we consider that MyoG is a more useful myogenic marker for our cell isolates.

Analysis of myogenic marker expression revealed that our myogenic cell isolates contained a mixture of Pax7+ immature cells, MyoD+ myogenic progenitor cells/myoblasts and further committed MyoG+ myocytes. During culture, they were able to form myotubes. Our results are in accordance with results showing that the population of mononuclear cells in the muscle is heterogeneous during early postnatal growth [58]. These cells are pre-quiescent and pass through distinct cell states during myogenic commitment accompanied by a characteristic time-dependent myogenic marker expression profile $[36,59,60]$. Whereas only $2-5 \%$ of myonuclei belong to $\mathrm{SC}$ in the adult stage, a much higher proportion (60\% in the pig) has been found during the early postnatal period, of which a large number $(90 \%)$ is in the cycling state $[5,9]$. This proliferating population mainly consists of $\operatorname{Pax} 7$ +/MyoD1+ cells and, to a lesser extent, of Pax7 
+/Myf5+ and MyoG+ cells marked for terminal differentiation $[5,18,58,61]$. This proliferative phase is necessary to generate progeny that differentiate and supply nuclei for growing myofibers. Simultaneously, increasing numbers of quiescent cells with selfrenewal potential emerge [58].

During postnatal growth, a SC pool is formed that shows marked molecular and functional heterogeneity, including the different expression of myogenic markers and the occurrence of distinct high- and low-dividing subpopulations [34, 37, 40]. In our study, the 4 day-old SP50/70 cultures differ from the SP40/50 and mixed P40/70 cultures by having a higher proportion of Pax7+ and MyoD1 + cells. As Pax7 has been shown to play a critical role in the early postnatal survival and expansion of SC $[16,62]$, this result is in accord with the dominance of SP50/70 (66\%) over SP40/50 (34\%) in freshly isolated cells. Moreover, Pax7 directs myogenic progenitors to withdraw from myogenic differentiation and to pass into a more dormant state, a prerequisite for their transition into the adult quiescent SC type [15, 63]. From our results, we can hypothesize that, during early postnatal muscle development, the dominant SP50/70 contributes markedly to the formation of the reserve cell/SC pool. Compared with early day 4 cultures, the proportion of Pax7+ cells decreases in day 8 cultures of mixed P40/70 and SP50/70, whereas it remains at about $10 \%$ in SP40/50.

Furthermore, the real-time monitoring of the adhesive behavior and complete growth kinetics of SC populations has revealed that SP40/50 and mixed P40/70 constitute a fast adhering and fast proliferating phenotype, whereas SP50/70 cells show considerably slower adhesion and exhibit a slow proliferation phenotype. A link between the adhesion ability and proliferation capacity of musclederived cells from turkey and human has also been found by Rouger et al. and Sellathurai et al. [12, 45]. Low- or nonadherent conditions are known to decrease the activation capacity of cells, to slow or arrest the cell cycle, and to reduce the activity of the main growth-factor-depending signaling pathways [27, 64-67]. In further experiments, an examination of whether cell attachment signaling pathways (e.g., integrin, focal adhesion kinase) and other adhesion molecules (e.g., laminin, N-CAM, and M-cadherin) contribute to the different adhesion/proliferation behavior of the separated subpopulations will be of interest.

Some of our results suggest the possible interaction between the cells of the two subpopulations. SC are embedded in their environmental niche and interact with their neighboring cells. As has recently been shown, SC interact with macrophages and endothelial cells, resulting in the modulation of SC functionality, e.g., proliferation and differentiation [68-70]. SP40/50 has a higher proliferation and differentiation potential than mixed P40/70 and SP50/70. In accord, the percentage of MyoG
+ cells in SP40/50 increases above that of SP50/70 and mixed P40/70 during culture, and SP 40/50 cells show a higher fusion rate and form a higher proportion of middle-sized and large myotubes. In other studies by Rouger et al. and Schultz [9, 37], fast-dividing SC populations also had a higher differentiation potential. In our study, the proliferation rates of mixed P40/70 and SP40/ 50 equalize during culture, whereas the differentiation behavior of mixed $\mathrm{P} 40 / 70$ exhibits more similarity to that of the slow-proliferating SP50/70 cells. Furthermore, compared with SP50/70, mixed P40/70 and, to a lesser extent, SP40/50 show a higher sensitivity to mechanical stress induced by medium change reflecting weaker adhesion to the surface. A sharp CI drop after medium change has also been observed in xCELLigence growth kinetic assays performed with other cells types, such as gingival fibroblasts and breast cancer stem cells $[71,72]$. Since mixed P40/70 includes cells of SP40/50 and SP50/70 (see Fig. 1a), we suggest that the latter trigger the adhesion behavior of SP40/50. However, until now, very little work has been carried out regarding cell communication and/or interaction between the various myogenic precursor cells. Thus, an analysis of the impact and the direction of possible interactions between SC populations will be of interest in future studies.

\section{Conclusions}

This study demonstrates that a discontinuous Percoll density gradient centrifugation is a useful tool for subdividing myogenic cell populations from perinatal porcine muscle into functionally divergent subpopulations. This approach allows SC heterogeneity to be analyzed to a greater extent, giving a better understanding of the way that individual cell populations are involved in the postnatal development and plasticity of skeletal muscle of pigs. Since the separation of subpopulations is based solely on differences in cell densities, we consider that this method, possibly with minor modifications, will also be applicable for other species.

\section{Abbreviations \\ Cl: Cell Index; DT: Doubling time; LD: Musculus longissimus dorsi; MPC: Myogenic precursor cells; SC: Satellite cells; SD: Standard deviation; SM: Musculus semimembranosus}

\section{Acknowledgements}

The authors thank Angela Steinborn and Christian Plinski for their technical assistance, Dr. Silvio Hering for experimental support, and Dr. Torsten Viergutz for scientific support with the flow cytometry analysis. They also thank the animal facility of the Leibniz Institute for Farm Animal Biology, headed by Dr. Bernd Stabenow, for taking care of the animals used in this study.

\section{Ethical approval}

The porcine muscles were isolated from animals obtained from the experimental pig unit of the Leibniz Institute for Farm Animal Biology. The animals were not part of an animal experiment, and their slaughter was notified according to German Law of Animal Protection. Animal husbandry and slaughter followed the guidelines set by the Animal Care Committee of 
the State of Mecklenburg-Western Pomerania, Germany, based on the German Law of Animal Protection.

\section{Funding}

Grants were provided by the FBN to CM (Future Fund). This research did not receive any grants from the commercial sector.

\section{Availability of data and materials}

All data that support the findings of this study are within the paper. Other relevant information is available from the corresponding author on reasonable request.

\section{Authors' contributions}

CM and MR designed the study. CM and KS performed the experiments and, together with MR, evaluated and interpreted the data. All authors were involved in the writing of the manuscript and approved the final version.

\section{Consent for publication}

Not applicable.

\section{Competing interests}

The authors declare that they have no competing interests.

\section{Publisher's Note}

Springer Nature remains neutral with regard to jurisdictional claims in published maps and institutional affiliations.

\section{Received: 24 October 2017 Accepted: 28 February 2018}

\section{Published online: 09 March 2018}

\section{References}

1. Biressi S, Tagliafico E, Lamorte G, Monteverde S, Tenedini E, Roncaglia E, Ferrari S, Ferrari S, Cusella-De Angelis MG, Tajbakhsh S, et al. Intrinsic phenotypic diversity of embryonic and fetal myoblasts is revealed by genome-wide gene expression analysis on purified cells. Dev Biol. 2007; 304(2):633-51.

2. Danoviz ME, Yablonka-Reuveni Z. Skeletal muscle satellite cells: background and methods for isolation and analysis in a primary culture system. Methods Mol Biol. 2012;798:21-52.

3. Mauro A. Satellite cell of skeletal muscle fibers. J Biophys Biochem Cytol. 1961:9:493-5.

4. Biressi S, Molinaro M, Cossu G. Cellular heterogeneity during vertebrate skeletal muscle development. Dev Biol. 2007;308(2):281-93.

5. Mesires NT, Doumit ME. Satellite cell proliferation and differentiation during postnatal growth of porcine skeletal muscle. Am J Physiol Cell Physiol. 2002; 282(4):C899-906

6. Moss FP, Leblond CP. Satellite cells as the source of nuclei in muscles of growing rats. Anat Rec. 1971:170(4):421-35.

7. Campion DR, Richardson RL, Reagan JO, Kraeling RR. Changes in the satellite cell population during postnatal growth of pig skeletal muscle. Anim Sci. 1981;52(5):1014-8.

8. Swatland HJ. Accumulation of myofiber nuclei in pigs with normal and arrested development. J Anim Sci. 1977;44(5):759-64.

9. Rouger K, Brault M, Daval N, Leroux I, Guigand L, Lesoeur J, Fernandez B, Cherel Y. Muscle satellite cell heterogeneity: in vitro and in vivo evidences for populations that fuse differently. Cell Tissue Res. 2004;317(3):319-26.

10. Ding S, Wang F, Liu Y, Li S, Zhou G, Hu P. Characterization and isolation of highly purified porcine satellite cells. Cell death discovery. 2017;3:17003.

11. Yablonka-Reuveni Z. The skeletal muscle satellite cell: still young and fascinating at 50. J Histochem Cytochem. 2011;59(12):1041-59.

12. Ceccarelli G, Benedetti L, Arcari ML, Carubbi C, Galli D. Muscle stem cell and physical activity: what point is the debate at? Open Med. 2017;12:144-56.

13. Kuang S, Kuroda K, Le Grand F, Rudnicki MA. Asymmetric self-renewal and commitment of satellite stem cells in muscle. Cell. 2007:129(5):999-1010.

14. Beauchamp JR, Heslop L, Yu DS, Tajbakhsh S, Kelly RG, Wernig A, Buckingham ME, Partridge TA, Zammit PS. Expression of CD34 and Myf5 defines the majority of quiescent adult skeletal muscle satellite cells. J Cell Biol. 2000;151(6):1221-34

15. Olguin HC, Olwin BB. Pax-7 up-regulation inhibits myogenesis and cell cycle progression in satellite cells: a potential mechanism for self-renewal. Dev Biol. 2004;275(2):375-88.
16. Oustanina S, Hause G, Braun T. Pax7 directs postnatal renewal and propagation of myogenic satellite cells but not their specification. EMBO J. 2004;23(16):3430-9.

17. Liu W, Wen Y, Bi P, Lai X, Liu XS, Liu X, Kuang S. Hypoxia promotes satellite cell self-renewal and enhances the efficiency of myoblast transplantation. Development. 2012;139(16):2857-65.

18. Neal A, Boldrin L, Morgan JE. The satellite cell in male and female, developing and adult mouse muscle: distinct stem cells for growth and regeneration. PLoS One. 2012;7(5):e37950.

19. Zammit PS, Relaix F, Nagata Y, Ruiz AP, Collins CA, Partridge TA, Beauchamp JR. Pax7 and myogenic progression in skeletal muscle satellite cells. J Cell Sci. 2006;119(Pt 9):1824-32.

20. Zouraq FA, Stölting M, Eberli D. Skeletal muscle regeneration for clinical application. In: Regenerative medicine and tissue engineering: InTech; 2013.

21. Musaro A, Barberi L. Isolation and culture of mouse satellite cells. Methods Mol Biol. 2010;633:101-11.

22. Yablonka-Reuveni Z, Quinn LS, Nameroff M. Isolation and clonal analysis of satellite cells from chicken pectoralis muscle. Dev Biol. 1987;119(1):252-9.

23. Mau M, Oksbjerg N, Rehfeldt C. Establishment and conditions for growth and differentiation of a myoblast cell line derived from the semimembranosus muscle of newborn piglets. In Vitro Cell Dev Biol Anim. 2008:44(1-2):1-5.

24. Jankowski RJ, Haluszczak C, Trucco M, Huard J. Flow cytometric characterization of myogenic cell populations obtained via the preplate technique: potential for rapid isolation of muscle-derived stem cells. Hum Gene Ther. 2001;12(6):619-28.

25. Li BJ, Li PH, Huang RH, Sun WX, Wang H, Li QF, Chen J, Wu WJ, Liu HL. Isolation, culture and identification of porcine skeletal muscle satellite cells. Asian Australas J Anim Sci. 2015;28(8):1171-7.

26. Gharaibeh B, Lu A, Tebbets J, Zheng B, Feduska J, Crisan M, Peault B, Cummins J, Huard J. Isolation of a slowly adhering cell fraction containing stem cells from murine skeletal muscle by the preplate technique. Nat Protoc. 2008;3(9):1501-9.

27. Sellathurai J, Cheedipudi S, Dhawan J, Schroder HD. A novel in vitro model for studying quiescence and activation of primary isolated human myoblasts. PLoS One. 2013;8(5):e64067.

28. Yablonka-Reuveni Z, Nameroff M. Skeletal muscle cell populations. Separation and partial characterization of fibroblast-like cells from embryonic tissue using density centrifugation. Histochemistry. 1987;87(1):27-38.

29. Bischoff R. Chemotaxis of skeletal muscle satellite cells. Dev Dyn. 1997; 208(4):505-15.

30. Kastner S, Elias MC, Rivera AJ, Yablonka-Reuveni Z. Gene expression patterns of the fibroblast growth factors and their receptors during myogenesis of rat satellite cells. J Histochem Cytochem. 2000;48(8):1079-96.

31. Che X, Guo J, Wang B, Bai Y. Rapid isolation of muscle-derived stem cells by discontinuous Percoll density gradient centrifugation. In Vitro Cell Dev Biol Anim. 2011:47(7):454-8.

32. Fumarola D, Antonaci S, Jirillo E, Munno I, Lucivero G, Bonomo L. Percoll density gradient centrifugation. (an improved method for the enrichment of lymphocyte subsets mediating different activities). La Ricerca in clinica e in laboratorio. 1982:12(3):485-91.

33. Li Z, Gilbert JA, Zhang Y, Zhang M, Qiu Q, Ramanujan K, Shavlakadze T, Eash JK, Scaramozza A, Goddeeris MM, et al. An HMGA2-IGF2BP2 axis regulates myoblast proliferation and myogenesis. Dev Cell. 2012;23(6):1176-88.

34. Chakkalakal JV, Christensen J, Xiang W, Tierney MT, Boscolo FS, Sacco A Brack AS. Early forming label-retaining muscle stem cells require p27kip1 for maintenance of the primitive state. Development. 2014;141(8):1649-59.

35. Zammit PS. All muscle satellite cells are equal, but are some more equal than others? J Cell Sci. 2008;121(Pt 18):2975-82.

36. Biressi S, Rando TA. Heterogeneity in the muscle satellite cell population. Semin Cell Dev Biol. 2010;21(8):845-54.

37. Schultz E. Satellite cell proliferative compartments in growing skeletal muscles. Dev Biol. 1996;175(1):84-94.

38. White RB, Bierinx AS, Gnocchi VF, Zammit PS. Dynamics of muscle fibre growth during postnatal mouse development. BMC Dev Biol. 2010;10:21.

39. Shinin V, Gayraud-Morel B, Gomes D, Tajbakhsh S. Asymmetric division and cosegregation of template DNA strands in adult muscle satellite cells. Nat Cell Biol. 2006:8(7):677-87.

40. Ono Y, Masuda S, Nam HS, Benezra R, Miyagoe-Suzuki Y, Takeda S. Slowdividing satellite cells retain long-term self-renewal ability in adult muscle. J Cell Sci. 2012;125(Pt 5):1309-17. 
41. Baquero-Perez B, Kuchipudi SV, Nelli RK, Chang KC. A simplified but robust method for the isolation of avian and mammalian muscle satellite cells. BMC Cell Biol. 2012;13:16.

42. Doumit ME, Merkel RA. Conditions for isolation and culture of porcine myogenic satellite cells. Tissue \& cell. 1992;24(2):253-62.

43. Henckel PR, Theil PK, Sorensen IL, Oksbjerg N. Temporal changes in glycogenolytic enzyme mRNAs during myogenesis of primary porcine satellite cells. Meat Sci. 2007;75(2):248-55.

44. Yi Z, Hathaway MR, Dayton WR, White ME. Effects of growth factors on insulin-like growth factor binding protein (IGFBP) secretion by primary porcine satellite cell cultures. J Anim Sci. 2001;79(11):2820-6.

45. Miersch C, Stange K, Hering S, Kolisek M, Viergutz T, Rontgen M. Molecular and functional heterogeneity of early postnatal porcine satellite cell populations is associated with bioenergetic profile. Sci Rep. 2017;7:45052.

46. Bischoff R, Heintz C. Enhancement of skeletal muscle regeneration. Dev Dyn. 1994;201(1):41-54.

47. Xi B, Yu N, Wang X, Xu X, Abassi YA. The application of cell-based label-free technology in drug discovery. Biotechnol J. 2008;3(4):484-95.

48. Atienza JM, Zhu J, Wang $X, X u X$, Abassi Y. Dynamic monitoring of cell adhesion and spreading on microelectronic sensor arrays. J Biomol Screen. 2005;10(8):795-805.

49. Ke N, Wang X, Xu X, Abassi YA. The xCELLigence system for real-time and label-free monitoring of cell viability. Methods Mol Biol. 2011;740:33-43.

50. Shi X, Garry DJ. Muscle stem cells in development, regeneration, and disease. Genes Dev. 2006:20(13):1692-708.

51. Witzel F, Fritsche-Guenther R, Lehmann N, Sieber A, Bluthgen N. Analysis of impedance-based cellular growth assays. Bioinformatics. 2015;31(16):2705-12.

52. Limame R, Wouters A, Pauwels B, Fransen E, Peeters M, Lardon F, De Wever $O$, Pauwels P. Comparative analysis of dynamic cell viability, migration and invasion assessments by novel real-time technology and classic endpoint assays. PLoS One. 2012;7(10):e46536.

53. Yablonka-Reuveni Z, Anderson SK, Bowen-Pope DF, Nameroff M. Biochemical and morphological differences between fibroblasts and myoblasts from embryonic chicken skeletal muscle. Cell Tissue Res. 1988; 252(2):339-48.

54. Alexander LS, Seabolt BS, Rhoads RP, Stahl CH. Neonatal phosphate nutrition alters in vivo and in vitro satellite cell activity in pigs. Nutrients. 2012;4(6):436-48.

55. Zhu H, Park S, Scheffler JM, Kuang S, Grant AL, Gerrard DE. Porcine satellite cells are restricted to a phenotype resembling their muscle origin. J Anim Sci. 2013;91(10):4684-91.

56. Allen RE, Rankin LL, Greene EA, Boxhorn LK, Johnson SE, Taylor RG, Pierce $P R$. Desmin is present in proliferating rat muscle satellite cells but not in bovine muscle satellite cells. J Cell Physiol. 1991;149(3):525-35.

57. Kaufman SJ, Foster RF. Replicating myoblasts express a muscle-specific phenotype. Proc Natl Acad Sci U S A. 1988;85(24):9606-10.

58. Tajbakhsh S. Skeletal muscle stem cells in developmental versus regenerative myogenesis. J Intern Med. 2009;266(4):372-89.

59. Zammit PS, Golding JP, Nagata Y, Hudon V, Partridge TA, Beauchamp JR. Muscle satellite cells adopt divergent fates: a mechanism for self-renewal? J Cell Biol. 2004;166(3):347-57.

60. Tierney MT, Sacco A. Satellite Cell Heterogeneity in Skeletal Muscle Homeostasis. Trends Cell Biol. 2016;26(6):434-44.

61. Day K, Paterson B, Yablonka-Reuveni Z. A distinct profile of myogenic regulatory factor detection within Pax7+ cells at S phase supports a unique role of Myf5 during posthatch chicken myogenesis. Dev Dyn. 2009;238(4):1001-9.

62. Diao Y, Guo X, Li Y, Sun K, Lu L, Jiang L, Fu X, Zhu H, Sun H, Wang H, et al. Pax3/7BP is a Pax7- and Pax3-binding protein that regulates the proliferation of muscle precursor cells by an epigenetic mechanism. Cell Stem Cell. 2012;11(2):231-41.

63. Lepper C, Conway SJ, Fan CM. Adult satellite cells and embryonic muscle progenitors have distinct genetic requirements. Nature. 2009; 460(7255):627-31

64. Dike LE, Farmer SR. Cell adhesion induces expression of growth-associated genes in suspension-arrested fibroblasts. Proc Natl Acad Sci U S A. 1988; 85(18):6792-6.

65. Schwartz MA, Ginsberg MH. Networks and crosstalk: integrin signalling spreads. Nat Cell Biol. 2002;4(4):E65-8.
66. Moro L, Dolce L, Cabodi S, Bergatto E, Boeri Erba E, Smeriglio M, Turco E, Retta SF, Giuffrida MG, Venturino M, et al. Integrin-induced epidermal growth factor (EGF) receptor activation requires c-Src and p130Cas and leads to phosphorylation of specific EGF receptor tyrosines. J Biol Chem. 2002;277(11):9405-14.

67. Schutt BS, Langkamp M, Rauschnabel U, Ranke MB, Elmlinger MW. Integrinmediated action of insulin-like growth factor binding protein-2 in tumor cells. J Mol Endocrinol. 2004;32(3):859-68.

68. Christov C, Chretien F, Abou-Khalil R, Bassez G, Vallet G, Authier FJ, Bassaglia Y, Shinin V, Tajbakhsh S, Chazaud B, et al. Muscle satellite cells and endothelial cells: close neighbors and privileged partners. Mol Biol Cell. 2007;18(4):1397-409.

69. Cornelison DD. Context matters: in vivo and in vitro influences on muscle satellite cell activity. J Cell Biochem. 2008;105(3):663-9.

70. Chazaud B, Sonnet C, Lafuste P, Bassez G, Rimaniol AC, Poron F, Authier FJ, Dreyfus PA, Gherardi RK. Satellite cells attract monocytes and use macrophages as a support to escape apoptosis and enhance muscle growth. J Cell Biol. 2003;163(5):1133-43.

71. Wyganowska-Swiatkowska M, Kotwicka M, Urbaniak P, Nowak A, SkrzypczakJankun E, Jankun J. Clinical implications of the growth-suppressive effects of chlorhexidine at low and high concentrations on human gingival fibroblasts and changes in morphology. Int J Mol Med. 2016;37(6):1594-600.

72. Pham PV, Nguyen NT, Nguyen HM, Khuat LT, Le PM, Pham VQ, Nguyen ST, Phan NK. A simple in vitro method for evaluating dendritic cell-based vaccinations. OncoTargets and therapy. 2014;7:1455-64.

\section{Submit your next manuscript to BioMed Central and we will help you at every step:}

- We accept pre-submission inquiries

- Our selector tool helps you to find the most relevant journal

- We provide round the clock customer support

- Convenient online submission

- Thorough peer review

- Inclusion in PubMed and all major indexing services

- Maximum visibility for your research

Submit your manuscript at www.biomedcentral.com/submit
Biomed Central 